that the intensity of the pulmonary sound was increased by increase of bloor pressure in the pulmonary arterial system. Why should not the same resuit follow increased pressure in the systemic arteries?

Dr. Garland, of Massachusetts, stated that it was often difficult to decide whether a murmur was coincident with, or replaced the cardiac sound. This is important to decide in diagnosis. He spoke of the importance of getting rid of the respiratory movements in trying to determine this point. A murmur will sometimes disappear when the breath is held for a moment. A deceptive murmur is sometimes heard at the base of the heart, to the right or the left of the sternum and up and down its border. It is systolic in time. The peculiarity of this murmur is that it disappears on full inspiration.

Dr. Donaldson thought it a question whether or not the impulse of the heart could produce a sound. Muscular contraction does not produce a sound, or at least not of sufficient force to be heard without very delicate instruments. Experiments have shown that the first sound is produced by the closure of the mitral and tricuspid valves. Where these have been prevented from closing the sound has been absent. In regard to presystolic murmurs, Dr. Leamy, of New York, has claimed with much plausability that they are not really presystolic, but that they occur at the beginning of the systole.

Dr. Flint in concluding the discussion, said that many of the points advanced were in reference to the mechanism of the sounds and in regard to murmurs. These he had not touched on in his paper, and therefore he waived any consideration of them at this time. His paper was concerned solely with the clinical aspects of the heart sounds. In regard to the Germans having taught the subject in the same manner as he did, he would call attention to the fact that 26 years ago he had pointed out this plan. He could not explain why the blood pressure acted differently in the pulmonic and systemic arteries, but such appears to be the fact.

\section{THE MULTIPLE WEDGE PRINCIPLE IN THE TREATMENT OF ORGANIC STRICTURES OF THE URETHRA.}

BY JNO. S. COlEman, M.D., Augusta, GA.

Read before the American Surgical Association, Washington, D. C.,

It is now nine years since I published, in the Medical Record of New York, my application of the multiple wedge principle to the treatment of organic strictures of the urethra.

To quote from that paper: "It ought to be a self-evident proposition, that it is easier to introduce singly the component parts of a wedge, than to introduce it as a whole. Take, for example, a No. I 2 conical bougie, even capillary at its point, and attempt to introduce it into a stricture: Where is the point of friction and resistance? Is it not around the entire circumference of the stricture? Diminish the size of the instrument, and in a direct ratio, you diminish the amount of resistance. After having passed into a stricture one of these whalebone guides, the second has to overcome the friction and resistance of but half the circumference of the stricture, and the line of contact with the other bougie. Now that we have passed these two, we have a groove in front and behind them through which we can readily pass the third and fourth, having now to overcome the resistance of but one-fourth the circumference of the stricture and the two lines of contact with the instruments already in position."

Since that time, I have treated by this method some twenty-five or thirty cases with invariable success. There was not, in any case, marked febrile disturbance; but in some few cases there was sufficient constitutional irritation to cause me to suspend the treatment for a day or two.

It is my habit to give, as a prophylactic, full doses of quinine, say fifteen to twenty grains per day.

I will give in detail one case, as it fully illustrates my method.-Capt. H. D. F. presented himself for treatment of a stricture of twenty years' duration.

His urine was always voided with difficulty, and the act usually consumed from twenty to thirty minutes of his time.

There was marked cystitis, as evidenced by the abundant mucus and the decomposition of his urine. The fetor of his urine was so great as to necessitate the immediate removal of the " pot de chambre." His strictures had been ruptured twice during the year 1866 , and once in 1867 , with Holt's divulsor.

Since the last operation, he had wholly neglected himself. March 16,1879 , after a prolonged and tedious effort, I succeeded in worming through his stricture one of the smallest-sized French filiform bougies, and securely tied it in situ. Five days afterwards I succeeded in introducing a second by the side of the first, but the cicatricial tissue was so dense and unyielding, that it was not until the fifteenth day that I could pass the third.

On the twenty-fifth day I readily passed the fourth and fifth bougie.

On the twenty-eighth day I introduced the sixth.

At no time was there any hindrance to the passage of the urine.

Feeling assured that now the caliber of the urethra would admit a good-sized instrument, I attempted to remove the bundle of filiforms. In this I was disappointed, for a sufficient amount of concretion had formed to prevent their removal en masse. The string binding them together was cut, when they were readily removed, until the last (the first one introduced) which required some little force to withdraw it. Three inches of its distal end had been covered by a phosphatic concretion. About one-half the deposit had slipped off the bougie in its withdrawal. (In subsequent cases I have obviated this contretemp by removing from time to ime those first introduced and replacing them by new instruments). My patient was now so nervous that he would not permit me to use a sound.

On the twenty-ninth day, retention of urine having 
occurred, the patient was chloroformed and a No. 9 steel sound (American scale) readily passed until it reached the prostatic urethra, where it was arrested by the calculous mass. With a little force it easily entered the bladder. To prevent the possibility of another stoppage, to still further cause the absorption of the cicatricial material, and for the purpose of irrigation, I now introduced and tied in a No. I 6 Nelaton catheter. Twice daily, a solution of salicylic acid and quinine was injected into the bladder, thoroughly washing it out.

On the thirty-eighth day No I 6 was removed, and No. 18 introduced and kept in place four days.

Steel sounds were now passed, from time to time, until the urethra was dilated up to No. 30 of the French scale. The concretions left in the bladder were all extruded within a week. (These specimens, together with the bougie, are here presented).

The patient was instructed to pass, from time to time, a large-sized sound.

It is now five years since Capt. F. was under treatment, and there has not been, so far as I know, a single symptom of a return of his disease. I know that many of my associates will object to the multiple wedge because of its tediousness.

I claim for it safety, certainty, and a greater immunity from a return of the disease, than by any other treatment knozen to me. Also that it will obviate the necessity for divulsion, internal or external urethrotomy. My reasons for not accepting any of the above operations are: First; that they subject the patient to an unnecessary risk of life. Second; that in internal urethrotomy from behind forwards, it is necessary to dilate the stricture to the caliber of a No. 7 or No. y English scale before the instrument can be used. Third; that internal urethrotomy from without inwards is, under favorable circumstances, uncertain. Even with Mr. Teeran's tunnelled urethrotome (which I consider least objectionable), mistakes are liable to occur, vide his articie in the American reprint of the London Lancet for i874, page 210, wherein he states that one of Dr. Gouley's whalebone guides "was cut in two about its centre, six inches of the whalebone being left behind in the stricture. As the patient experienced no pain from its presence, I determined to leave it in the urethra, in the hope that it would set up a profuse discharge, and so facilitate the treatment. In this expectation I was, however, disappointed, and on December $\mathbf{I}$, I removed the broken portion of the bougie after its seven days' imprisonment."

One of the gravest and most obstinate of my cases was that of a gentleman who, under the care of another practitioner (one whom Sir Henry Thompson characterizes as a "knowing man at anatomy"), had been subjected to a forced entrance into the bladder. Pyamia followed as a result of this violence, with the formation of five abscesses; one at the posterior border of the right scapula, and from which was evacuated at least one gill of pus; one beneath the left tensor vagina femoris; one beneath the right vastus internus, and which I believe reached the popliteal space; and one upon each internal malleolus.

The life of this patient trembled in the balance for weeks, but he finally inade a thorough and complete recovery. His stricture was subsequently relieved by the multiple wedge. My friend Dr. H. F. Campbell, who saw this case in consultation with me, said that it was the only case of pyæmia which he had ever known to recover. I concur in the axiom first enunciated by Professor Syme, that "whenever urine passes outwards through a stricture, an instrument ought with care and perseverance to be got in." Also in the dictum of Sir Henry Thompson: "first and foremost, dilatation-dilatation alzvays-dilatation without exception whenever it will succeed." (Italics mine). In corroboration of my position, I beg leave to make the following quotations:

Dr. Frank H. Hamilton, in his "Principles and Practice of Surgery," says of organic stricture: "To the question so often repeated by inexperienced surgeons-What proportion of organic strictures can be successfully treated by gradual dilatation? we answer unhesitatingly, almost every stricture into which the smallest sound or bougie can be introduced. And to the question which naturally follows, are there any strictures, through which urine can pass, which cannot be entered by instruments, we reply, that we have seldom or never met with them, and that such examples must, at least, be exceedingly rare. It is not pretended that all strictures of this class can be entered at once; but only with patience, perseverance, and skill, within a few weeks, or months at most, they will in all probability yield to the instruments, and the bladder will be safely entered.

"It is an error to suppose that a stricture treated by caustic or incision is cured any more thoroughly than when it has been treated by dilatation, or, as it might be more properly called, by absorption. There is no soundness in the theory upon which the claim is attempted to be sustained ; and there is no experience to justify the assumption. We have observed the results of all these forcible methods in many cases; and there is the same tendency in all of them to a return of the stricture, unless the dilatation is afterwards maintained by the occasional and regular introduction of instruments. The only objection that can be offered to gradual dilatation, then, is the length of time it may require to complete the cure, as contrasted with forcible dilatation, caustic, incision and perineal section; but, on the other hand, it cannot be denied that, in point of safety, gradual dilatation has greatly the advantage. Death is seldom or never the result of the latter procedure; but from all that we have seen and heard of the other methods, they are followed by a mortality equal to five or seven per cent. Nor does it seem to vary much whether caustic, internal incision, forcible dilatation, or perineal section have been employed. Indeed, some gentlemen of large experience, who favor frequent incisions, admit a mortality of not less than seven per cent, , and regard it as a flattering testimony to the excellency of their practice, because in very many surgical operations which are deemed justifiable the mortality is twenty-five or fifty per cent. The fallacy of the argument is too apparent to require exposure. If one is convinced, however, that the condition of the patient demands speedy 
relief, or if it should happen that the stricture will not yield to gradual dilatation, the surgeon may resort to some one of the other methods already named, and which we shall now proceed to describe."

Dr. Otis, in his paper on stricture of the male urethra, its radical cure, $\mathbf{1} 875$, closes with the following paragraph: "Strictures of a caliber of less than 16 or 18 of the French scale ( 7 or 9 of the English), and hence below the capacity of the dilating urethrotome as at present constructed, require enlargement by gradual dilatation with soft bougies, when this is well borne; if not, by divulsion or the urethrotome of M. Maisonntuve.

After having been brought by any one of these methods above referred to, up to a capacity permitting the passage of the dilating urethrotome, complete divulsion of the stricture by means of this instrument may readily be effected." (Italics mine.)

In Dr. Sands' reply to Dr. Otis, on spasmodic stricture of the urethra, he says: "I have seen, in consultation, persons who have suffered from troublesome hæmorrhage, varying in duration from a few days to a month, in consequence of having been cut with the dilating urethrotome-an excellent instrument of its kind, but the use of which has been carried to a dangerous excess. Finally, I have heard of a number of cases in which death has resulted from the employment of the dilating urethrotome. It is hard to obtain access to these fatal cases, which are not usually reported, and which are generally considered a kind of private property. I can state with authority, however, that three fatal cases of operation with the dilating urethrotome have lately happened in our city hospitals, two of which occurred last week in one hospital.

"In two of the cases mentioned, death took place from pyæmia within a week of the operation. In the third case, death occurred from uræmia on the sixteenth day after the operation, which was performed for the division of an anterior stricture so slight as to be detectable only with a bulbous sound, No. 24 French. At the autopsy three deep incisions were found, involving the anterior $3 \frac{\mathrm{T}}{2}$ inches of the floor of the urethra, the mucous membrane of which, in this situation, was not thickened, and showed no appearance of disease to the eye.

"A tight organic stricture, undivided, was noticeable at the bulbo-membranous junction. This, during life, had been treated by dilatation."

In the American reprint of the London Lancet, for I 874 , page 404, Mr. Teeran, in his "Description of a Catheter Urethrotome with Conducting Bougie," says : "Then again, most of the urethrotomes are so large at their vesical extremity that they cannot be used, unless the urethra has been previously dilated up to a certain caliber. This remark especially applies to those urethrotomes that divide from behind forwards. For a urethrotome, to be a safe and efficient instrument for the division of tight strictures in the deeper portions of the urethra, it must possess two important qualities: Firstly, its vesical extremity must be so fine that it can be introduced through very tight strictures. It consequently follows that the urethrotome must be one which divides from be- fore backwards, for, if the stricture be capacious enough to permit an instrument to pass which cuts from behind forwards, the indication for any operation is doubtful; for, if we have dilated the urethra up to half its natural caliber, why should we not persevere with the treatment which has been so successful, and that, too, in the worst and most troublesome stage of the complaint? (Italics mine.) What we want is to save time in certain cases, where patients have, for instance, to go to sea suddenly, and where time does not permit of a course of treatment by gradual dilatation.'

In the abstract of Guy's Hospital reports in the American Journal of the Medical Sciences, for January, 1879 , page 178 , the following views are quoted from Mr. Cooper Forster: " $\mathrm{He}$ has done external urethrotomy only once in the last seven years, and then regretied it afterwards, and he has never performed internal urethrotomy.

"He relies on the hot bath, opium, and gradual dilatation."

M. Despres, in a communication to the Societé de Chirurgie, October $\mathbf{1 6}, \mathbf{1} 878$, on the extraction of prostatic calculus, "did not wish to perform urethrotomy, as he considers this an operation which renders stricture more fibrous and resisting." (Italics mine.)

In the American reprint of the London Lancet, for February, I879, page 7 I, I find the following emphatic language from Mr. Messenger Bradley upon the subject of internal urethrotomy:

"In boldly criticising it, then, as dangerous and unsatisfactory, I would have you remember that it is criticism of one who has never performed it, and who, I think I may add, never will."

Sir Henry Thompson, in his "Clinical Lectures on Diseases of the Urinary Organs," and, than whom, upon this subject, there is no higher authority, fully sustains me in the position I have assumed. Vide page 32 of the above mentioned monograph :

"I will touch lightly on the continuous dilation or the tying in of the instrument. There is a patient up-stairs who is now undergoing it successfully. You have tried, we will suppose, the simple dilatation, and have not made the amount of progress desired, or perhaps the patient's avocations may make it necessary to have a more speedy cure. In either case you may say, if you can give me ten or fourteen days in your room, not necessarily in bed, but on the sofa quietly at home, I can almost certcinly bring you from the smallest number up to the highest-that is, by continuous dilatation." As to the length of time required, Sir Henry claims greater potency for the continuous method than I have, as yet, been able to obtain. "In simple dilatation the instrument is sim. ply introduced and withdrawn; in continuous, you tie the instrument in, and allow it to remain for several days. You tie in a small catheter, which, if possible, is to be gum elastic, and so that it just enters the bladder. And you should always take care that it is small enough to pass easily, so that it lies loosely in the canal. Those three conditions being granted, this is one of the safest and best modes of treating stricture." (Italics mine.) 
In response to a note of inquiry, my friend, Dr. Eugene Foster, nember of the American Public Health Association, and President of the Georgia State Medical Association, kindly furnishes me with the following communication :

Augusta, Ga., Nov. 23, I 883.

DEAR DOCTOR:-In reply to your letter of the 22nd, asking my experience in treating strictures of the urethra by your multiple wedge principle, I beg to submit the following answer: I have treated sixteen cases of close organic stricture by your method (several of them of years' standing), and every one of them successful. Your plan of treatment has, in my hands, proven itself all that you claim for it. I am amazed that surgeons generally have not tested its merits, and long since given you credit for your valuable suggestions.

(Signed)

To Dr. Jno. S. Coleman.

Very truly yours,

Eugene Foster.

\section{CONCLUSIONS.}

In the foregoing paper the following are the principal precepts that have been advocated.

First: 'That in the treatment of organic strictures of the uretha, urethrotomy whether internal or external, and also the method by divulsion, are attended with serious risk to the patient on account of hæmorrhage, pyæmia and uremia.

Second: That strictures treated by these methods are no less liable to recurrence than those treated by gradual dilatation. Indeed, unless followed by persistent dilatation they are subject to early relapse.

Third: That gradual dilatation of urethral strictures, though of slower progress in the beginning, is almost entirely free from danger, more permanent in its results, and upon the whole the shortest and most perfect method of cure.

Fourth: That in the treatment of tight urethral strictures the Multiple Wedge Principle devised by the writer, viz.: That of introducing side by side and one at a time successively a number of filiform bougies, whether applied to the interrupted, or the continuous method, offers to the surgeon the easiest, safest and best method for effecting the solution, or absorption of the inodular tissue, and for removing the obstruction.

NOTE.

In the discussion of the above paper, as reported by the Medical Record of New York, "Dr. Sayre thought it somewhat strange that the author of this paper claimed to be the originator of the Multiple Wedge System, since, to his personal knowledge, this system had been in use in Bellevue Hospital, New York, for at least twenty years. "- To me, it is passing strange that my friend, Prof. J. W. S. Gouley, a member of the staff of Bellevue, and, the author of one of the best monographs on "Diseases of the Urinary Organs," should not have appreciated a system whiclt, according to Dr. Sayre, had then been in use in the hospital for eleven years. That he did not do so is manifest from the following language in his letter to me of date Dec. 9th, I874: "I have myself wedged in two and sometimes three of these bougies side by side, and have thus rendered otherwise impassible strictures amenable to ordinary dilatation. Three years ago, I had some probe-pointed whalebone bougies made very small (capillary) for the first two inches from the vesical end and thence increasing gradually to Nos. $1 / 2,1,2,3$ and 4 , so that I could accomplish more dilatation with a single bougie at one sitting than I could with two or three ordinary whalebone capillary bougies introduced side by side." (Italics mine.) I claim to have made the Multiple Wedge Principle a system for the treatment of tight, close, otherwise impassible strictures; to have given it a name, and, to have been the first to make it known to the profession.

Whewell says: "Names record discoveries."

\section{SPECIFIC TREATMENT OF DIPHTHERIA AND CBOUP.}

BY GEO. A. LYNN, M.D., MONONGAHELA CITY, PA.

Read to Section on Practice of Medicine and Materia Medica of American Medical Association, May, 1884.

The efforts of many earnest workers in the medical profession, have of late years been directed toward investigating and seeking to isolate the causes of disease. And the tendency is to ascribe the cause of a class of diseases to the presence in the human body of a contagium, spore, or morbific germ, producing zymosis, with more or less intense disturbance of general nutrition, with or without local lesion of the solids.

As yet none of these have been satisfactorily determined. And while this work is necessary to the advancement of medical science, yet it would be of little avail to the human family to isolate, classify, and describe a morbific element, so long as we have no antidote for it, or means of protecting the human body from its ravages.

Prof. William Pepper, in his address on medicine, delivered before this association at Richmond in I 88I, said : "It is clear that if we possessed a perfect antidote for the poison of a zymotic disease. our medicinal treatment would resolve itself into the administration of that antidote in suitable doses and forms, with due regard to the state of the digestive organs.

It seems yet presumptuous to hope that we shall ever possess such antidotes for the acute infectious diseases as we have for syphilis and malaria. But I cannot omit a passing reference to the remarkable results that have recently been observed to follow the use of large doses of bichloride of mercury in diphtheria."

After stating that the subject was brought to his notice, by a paper I read before the Washington County Medical Society, and published in the Transactions of the State Medical Society of Pennsylvania for the year 1879 , - he gave a notable example of the efficacy of the treatment in a desperate case of diphtheria under his own observation, in which the result was highly satisfactory. And added, "The 